\title{
An Outbreak of Hepatitis E Virus in Raipur, Chhattisgarh, India in 2014: A Conventional and Genetic Analysis
}

Negi SS ${ }^{1 *}$, Barde PV ${ }^{2}$, Pathak $\mathbf{R}^{2}$, Gaikwad $\mathbf{U}^{1}$, Das $\mathrm{P}^{1}$ and Bhargav $A$

${ }^{1}$ Department of Microbiology, All India Institute of Medical Sciences, Tatibandh, GE Road, Raipur, Chhattisgarh, India

${ }^{2}$ National Institute for Research in Tribal Health (ICMR), Nagpur Road, Jabalpur, Madhya Pradesh, India

\begin{abstract}
Study Background: An unprecedented outbreak of enterically transmitted acute hepatitis erupted in Raipur between April-June, 2014 claiming lives of 23 persons including 8 pregnant women. It was investigated by serological, biochemical and molecular methods to reveal its etiological agent, prevalence and genotype responsible for the outbreak.

Methods: A total of one hundred six (106) blood samples from equal number of suspected cases of acute hepatitis cases presented in AlIMS Raipur for treatment were investigated for Anti-HEV IgM, Anti-HAV IgM, LFT, RT-PCR and sequencing.

Results: Serological analysis incriminated HEV as the chief causative agent of this outbreak with attack rate of $68.8 \%$ followed by HAV (9.4\%) while dual infection was noted in 2 cases (1.8\%). Mortality rate of 2.87 per 10,000 population and incidence rate of $1.7 \%$ were recorded. In comparison to children and elderly cases, adults age group were more affected with men had higher attack rate than women and children $(p<0.01) .98 \%$ cases had moderate to severely deranged LFT level. nRT-PCR and sequencing analysis confirmed the presence of HEV genotype 1a.

Conclusion: Contamination of municipal water pipelines by sewage drain had triggered this outbreak caused predominantly by HEV genotype 1a with few HAV cases. This warranted the health and municipal authorities to change the defaulted water pipeline and segregate it from sewage drain resulting in progressive decline of this ill feted outbreak.
\end{abstract}

Keywords: Central India; Genotype 1a; Hepatitis E; Outbreak

\section{Introduction}

Hepatitis E virus(HEV) and Hepatitis A Virus(HAV) are enterically transmitted viruses of public health importance due to their ability to cause sporadic, endemic and epidemic outbreaks mostly associated with sewage contamination of drinking water especially in developing countries [1,2]. HAV despite worldwide distribution cause rare epidemic involving mainly infants and young children and they develop protective immunity till the adult age is attained [2,3]. HEV, on the other hand frequently reported to cause epidemics in developing countries affecting older children and young adults and is reported to affect 20million people worldwide with over 3 million acute cases and about 56,600 deaths every year $[1,4]$. In India, HEV is reported to be endemic accounting for $50-70 \%$ of sporadic outbreaks of enterically transmitted hepatitis [3]. Although, HEV generally cause mild hepatitis in young to middle aged adults (15-40year old) and treatment remains symptomatic, severity can be exorbitant by causing fulminant hepatic failure (FHF) in pregnant women especially in third trimester wherein mortality can go as high as $20 \%$ as compared to $0.2-1 \%$ in general population [5].

The HEV belongs to family Hepeviridae genus Hepeviruses that has about $7.2 \mathrm{~kb}$ long positive sense, single stranded RNA genome [6]. The virus is having single serotype with four genotypes divided in to several sub-genotypes. It is reported that the infecting genotype/sub-genotype play a role in disease severity and transmission, thus have important epidemiological implications [7]. Genotype 1 is known to be circulating in North, West and South India; however no genotypic information is available from Central India [7-9].

Since the first documented outbreak of HEV from Delhi in 195556 , several outbreaks of HEV have been reported from different parts of India using a descriptive approach [7-11]. Singh et al, 1998 has reported
$68 \%$ of acute sporadic cases of viral hepatitis due to HEV and HAV on the basis of serological finding [10]. However no genotypic study has been done from central India. In April, 2014, health officials received reports of unprecedented upsurge in the number of cases of acute hepatitis from Raipur, the capital of Chhattisgarh state of India wherein 23 people including 8 pregnant women succumbed to infection. Local media and health personnel found the contamination of water pipelines with sewage drain at several parts of Raipur. All India Institute of Medical Sciences (AIIMS), Raipur being one of the main tertiary hospitals has been appointed for investigation and management of the suspected cases of acute hepatitis. Accordingly this outbreak was investigated with the objectives of (i) identifying the etiological agent by serological and molecular methods and assessing its demographic profile, (ii) genotyping and sub typing of the isolated HEV strain to understand epidemiology in central India and (iii) proposing appropriate control and preventive measures.

\section{Materials and Methods}

Study area and period

The suspected cases of acute hepatitis were reported to All India

*Corresponding author: Dr. Sanjay Singh Negi, Assistant Professor, Department of Microbiology, All India Institute of Medical Sciences, Tatibandh, GE Road, Raipur, Chhattisgarh, India, Tel: 08518881779; E-mail: negidr@gmail.com

Received August 26, 2015; Accepted Novmber 02, 2015; Published Novmber 04 2015

Citation: Negi SS, Barde PV, Pathak R, Gaikwad U, Das P, et al. (2015) An Outbreak of Hepatitis E Virus in Raipur, Chhattisgarh, India in 2014: A Conventional and Genetic Analysis. J Med Microb Diagn 4: 209. doi:10.4172/2161-0703.1000209

Copyright: $\odot 2015$ Negi SS, et al.. This is an open-access article distributed under the terms of the Creative Commons Attribution License, which permits unrestricted use, distribution, and reproduction in any medium, provided the original author and source are credited. 
Institute of Medical Sciences (AIIMS), Raipur, from different localities of Raipur, a capital of Chhattisgarh. The details included Deen Dayal Uppadhay Nagar (DDU) $(n=55)$, Hirapur $(n=23)$, Gudhiyari $(n=09)$, Daganiya $(n=05)$, Kabir Nagar $(n=06)$ and Sunder Nagar $(n=08)$ equaling to a total of 106 cases received between 20th April to 30th June, 2014 (Figure 1). Data from local census authority showed the population of the region as 79890 residents. We obtained information regarding demographic characteristics, area of residence and date of admission from all patients. Information was also generated from the patients for source of drinking water.

\section{Sample collection and age distribution parameter}

A total of Hundred and six (106) blood samples were received from equal number of suspected cases of acute hepatitis (60 male, 29 female and 17 children) in department of Microbiology, AIIMS, Raipur for serological diagnosis of HEV and HAV with inclusion criteria included was to enroll those cases that have jaundice with at least one of the following symptoms: Dark urine, fever, abdominal pain, vomiting and loss of appetite. Majority of the patients showed these clinical features of acute hepatitis with slight varying proportion (Figure 2). Age distribution comprised of distribution of suspected cases in three category viz., children and adolescent up to 17 years $(n=17$, male 11 , female 06), adults between $18-50$ years $(n=68$, male 46 , female 22$)$ and elderly above 50 years of age $(n=21,14$ male, 7 female). Since this study was done in response to public health emergency to investigate the outbreak, ethical clearance was not required.

\section{Laboratory investigation}

(i) Serological investigation: All sera samples were screened

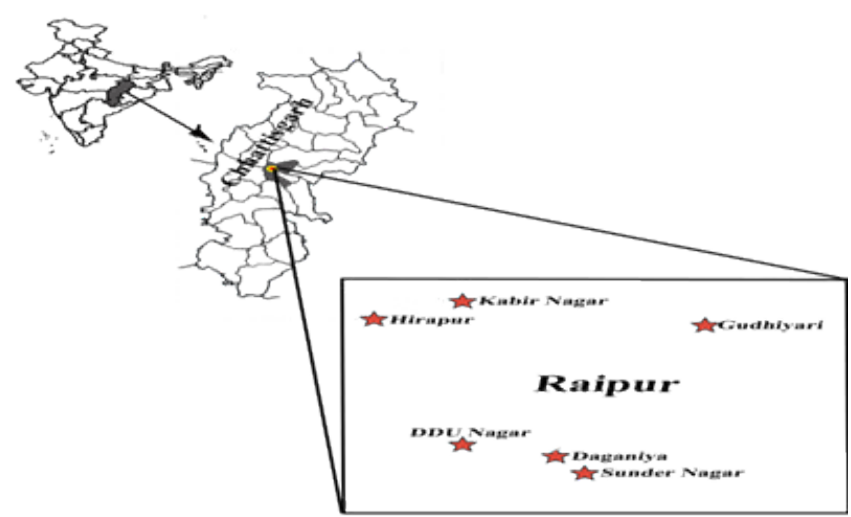

Figure 1: Map of India and Chhattisgarh Raipur (A) showing hepatitis affected areas in Raipur city in 2014 (Map not to the scale).

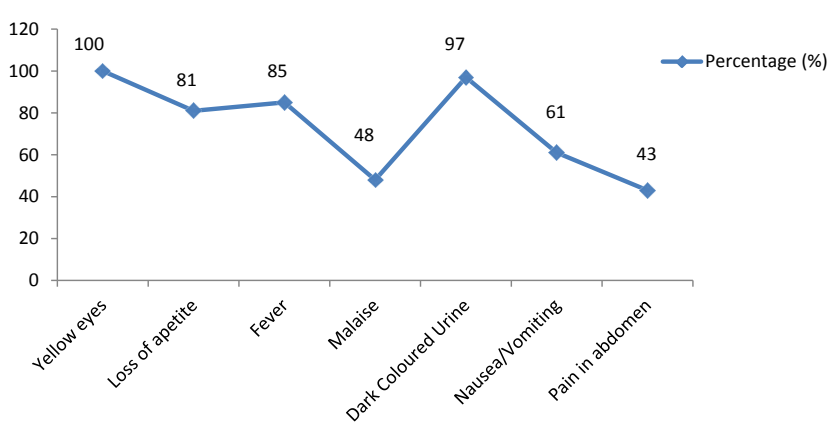

Figure 2: Clinical presentation of acute viral Hepatitis cases $(X$ Axis = clinical symptoms, $Y$ Axis= percent of the cases showing symptoms)

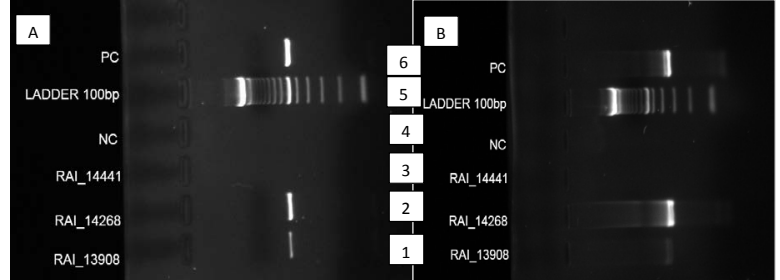

Figure 3: The Gel image showing diagnostic nRTPCR (A):RT-PCR of hepatitis E virus : lane 1 and 2 : showing RT-PCR products of 575 bases, lane 3: negative sample lane 4: Negative Control Lane 5: 100 bp ladder, Lane 6: Positive control (B): Showing nested of PCR of HEV product size 327 bases Lane 1,2: showing positive samples, lane 3: negative sample, lane 4: Negative control , 5: 100 bp ladder, lane 6: Positive Control

for IgM antibody to HEV and HAV using IgM capture ELISA kit (Immunovision, Springdale, AR, USA) in accordance with the manufacturer's instructions. The in-house anti-HEV and anti-HAV positive control was also used along with the kit controls.

(ii) Biochemical investigation: The following biochemical parameters were done for all the patients: (i) Total bilirubin, direct and indirect (ii) serum alanine aminotransferase (ALT), (iii) serum aspartate aminotransferase (AST) and (iv) alkaline phosphatase (ALP) in accordance with their respective kit protocols.

(iii) Molecular investigation: Randomly picked 17 HEV ELISA positive samples were tested by nested reverse transcriptase polymerase chain reaction (nRT-PCR) for confirmation of etiology as described by Kumar et al, 2007 [12] with minor modifications. Briefly the viral RNA was extracted using QIAgen's Viral RNA kit (QiagenGmbH, Germany), by following manufacturers protocol and the extracted RNA was subjected to RT- PCR using kit (Superscript One Step RT-PCR kit with Platinum ${ }^{\circ}$ Taq DNA Polymerase, Catalogue Number: 12574-018, Invitrogen, USA) following manufacturer protocol. For phylogenetic analysis, nRT PCR as described by Arankalle et al. [13] for ORF 1 was used (Table 1). The nested PCR products of $(n=05)$ samples were subjected to sequencing as described earlier [14]. The resulting sequences were curated and submitted to the GenBank.

\section{Data Analysis}

Prevalence of HEV and HAV affect in this outbreak were statistically compared in males, females and children by Chi square test $(\chi 2)$ using Stata statistical software(release 5.0; Stata Corporation, USA). To establish genotype and sub type, sequences obtained from our study were compared with 20 representative NCBI sequences of all genotypes

Table 1: Primers with their sequences(5' to $\left.3^{\prime}\right)$.

\begin{tabular}{|c|c|c|c|}
\hline Primer & Gene & Sequence & $\begin{array}{l}\text { Product } \\
\text { Size }\end{array}$ \\
\hline Hep E 1F $(O)^{*}$ & ORF 1 & $\begin{array}{l}\text { CCA CAC ACA TCT GAG CTA CAT } \\
\text { TCG TGA GCT }\end{array}$ & \multirow{2}{*}{$575 b p$} \\
\hline Hep E 1R $(O)^{*}$ & ORF 1 & $\begin{array}{l}\text { AGG CAT CCA TGG TGT TTG AGA } \\
\text { ATG AC }\end{array}$ & \\
\hline Hep E 2F $\left(\right.$ Nest $\left.^{*}\right)$ & ORF 1 & CGA CTC CAC CCA GAA TAA CTT & \multirow[b]{2}{*}{$327 \mathrm{bp}$} \\
\hline $\begin{array}{l}\text { Hep E 2R } \\
\text { (Nest) }\end{array}$ & ORF 1 & $\begin{array}{l}\text { CAC AGC CGG CGA TCA GGA } \\
\text { CAG }\end{array}$ & \\
\hline RNAPEF\# & RNAPORF1 & $\begin{array}{l}\text { ACATTTGAATTMACAGACATT- } \\
\text { GTGC }\end{array}$ & \multirow{2}{*}{$826 b p$} \\
\hline RNAPER\# & RNAPORF1 & $\begin{array}{l}\text { ACACASATCTGWGCTACATTC- } \\
\text { GTGAG }\end{array}$ & \\
\hline RNAPIF\# & RNAPORF1 & GACGTGTCCAGGATCACCTTC & \multirow[b]{2}{*}{$535 b p$} \\
\hline RNAPIR\# & RNAPORF1 & $\begin{array}{l}\text { ACTCACTGCAAAGCACTATC- } \\
\text { GAATC }\end{array}$ & \\
\hline
\end{tabular}

*Primers used for diagnostic identification. ${ }^{12}$

\#Primer used for Phylogenetic analysis. 
Citation: Negi SS, Barde PV, Pathak R, Gaikwad U, Das P, et al. (2015) An Outbreak of Hepatitis E Virus in Raipur, Chhattisgarh, India in 2014: A Conventional and Genetic Analysis. J Med Microb Diagn 4: 209. doi:10.4172/2161-0703.1000209

Page 3 of 5

Table 2: Attack rate of HEV \& HAV versus age and gender distribution.

\begin{tabular}{|c|c|c|c|c|c|c|c|c|c|c|c|c|}
\hline \multirow[t]{2}{*}{ Age group } & \multicolumn{3}{|c|}{ No. of cases $(\%)$} & \multicolumn{3}{|c|}{$\begin{array}{c}\text { HEV } \\
\text { Number of cases (\%) }\end{array}$} & \multicolumn{3}{|c|}{$\begin{array}{c}\text { HAV } \\
\text { Number of cases (\%) }\end{array}$} & \multicolumn{3}{|c|}{ Dual HAV \& HEV } \\
\hline & Total & Male & Female & Total & Male & Female & Total & Male & Female & Total & Male & Female \\
\hline $0-17$ yrs & $17(16.0)$ & $11(64.7)$ & $6(35.2)$ & $10(58.8)$ & $7(41.1)$ & $3(17.6)$ & $3(17.6)$ & $2(9.5)$ & $1(5.8)$ & $1(5.8)$ & $1(5.8)$ & $0(0.0)$ \\
\hline $18-50$ yrs & $68(64.1)$ & $46(67.6)$ & $22(32.3)$ & $50(73.5)$ & $36(52.9)$ & $14(20.5)$ & $5(7.3)$ & $4(5.8)$ & $1(1.4)$ & $1(1.4)$ & $1(1.4)$ & $0(0.0)$ \\
\hline$>50$ yrs & $21(19.8)$ & $14(66.6)$ & $7(33.3)$ & $13(61.9)$ & $9(42.8)$ & $4(19.0)$ & $2(9.5)$ & $2(9.5)$ & $0(0.0)$ & $0(0.0)$ & $0(0.0)$ & $0(0.0)$ \\
\hline Total & 106 & $71(66.9)$ & $35(33.0)$ & $73(68.8)$ & $52(49.0)$ & $21(19.8)$ & $10(9.4)$ & $8(7.5)$ & $2(1.8)$ & $2(1.8)$ & $2(1.8)$ & $0(0.0)$ \\
\hline
\end{tabular}

Table 3: Zone wise outbreak of HEV \& HAV.

\begin{tabular}{|l|c|c|c|}
\hline Zone $(\mathrm{n}=$ number of cases received) & HEV & HAV & Dual infection of HAV \& HEV \\
\hline DDU $(n=55)$ & 39 & 1 & 2 \\
\hline Heerapur(n=23) & 15 & - & - \\
\hline Gudhiyari(n=9) & 6 & - & - \\
\hline Daganiya(n=5) & 3 & 2 & - \\
\hline Kabir Nagar(n=6) & 4 & - & - \\
\hline Sunder Nagar(n=8) & 6 & 10 & - \\
\hline Total $(n=106)$ & 73 & 2 \\
\hline
\end{tabular}

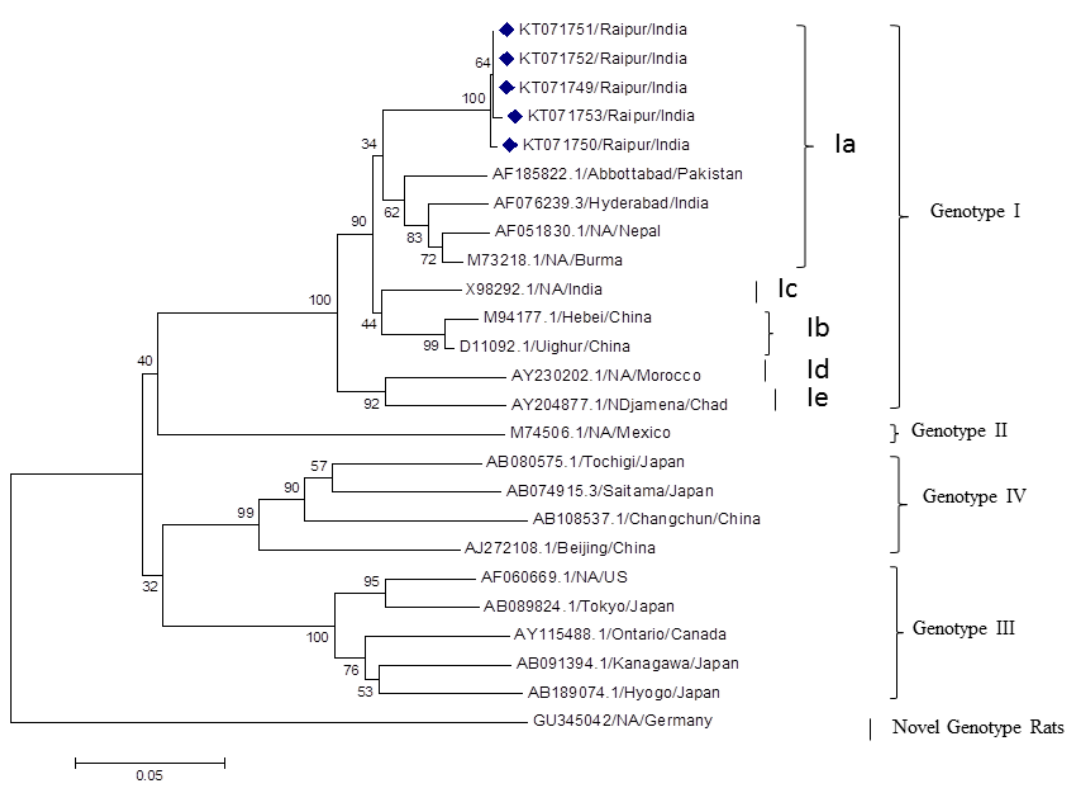

Figure 4: Phylogenetic tree of Hepatitis E virus generated by the NJ Method, based on the ORF1 (360bp) region. Reference strains are labeled with its accession number and country of origin followed by year of detection. The strains of our study are marked with ( $\supset$ ). Respective genotypes and sub-genotypes are marked after the bracket. Novel HEV genotype in rats used as outgroup. *NA=Place of origin not available.

using BioEdit v7.0.9 (Tom Hall Ibis Biosciences, USA). The multiple sequence alignment and phylogenetic analysis were performed using CLUSTAL $W$ and MEGA5 software [15] and the tree was generated with 1000 bootstrap replicates.

\section{Results}

Out of 106 suspected cases of acute hepatitis, a total of 85 cases were confirmed by serological investigation. HEV was found to be the predominant etiological agent responsible for acute hepatitis with attack rate of $68.8 \%$ ( 73 cases) alone whereas attack rate of HAV was found to be $9.4 \%$ (10 cases) and 2 cases (1.8\%) were found to have dual infection of HEV and HAV (Table 2). Age and gender parameter showed males $(n=71,66.9 \%)$ were mainly affected in this outbreak with $52(49.0 \%)$ were affected from HEV, 8(7.5\%) from HAV and 2 cases(1.8\%) were affected with both HEV and HAV in comparison to women $(n=35$, $33.0 \%)$ patients, wherein $21(19.8 \%)$ showed positive anti HEV IgM antibody and $2(1.8 \%)$ were found affected with HAV showing the significant difference $(\mathrm{p}<0.01, \mathrm{p}=0.9732)$. No dual infection was seen in women. Among individual category of children $(n=17), 10(58.8 \%)$ were found positive for HEV, 3(17.6\%) for HAV and 1(5.8\%) dual infection of HEV and HAV. In adult category (18-50years), maximum cases were reported. It included 50(73.5\%) cases of HEV, 5(7.3\%) of HAV and $1(1.4 \%)$ case of dual infection of HEV and HAV. In elderly category (>50years), HEV was found in $13(61.9 \%)$ cases and HAV in $2(9.5 \%)$ from a total of 21(19.8\%) suspected cases of acute hepatitis (Table 2).

Average age group affected in children and adolescent was 11.6yrs, in adults this statics was 28.12 yrs for men and 29.75 yrs for women, while 57.28 yrs in elderly age group above 50 .

The death of 23 patient's in initial stages of the outbreak on comparison with residential affected population $(n=79,890)$ revealed the mortality rate of 2.87 per 10,000 population. Maximum serological (ELISA positive) cases were confirmed from DDU Nagar [ $\mathrm{n}=55$ (HEV 
Table 4: Serum Bilirubin levels among serologically positive patients $(\mathrm{N}=85)$.

\begin{tabular}{|c|c|c|c|}
\hline Range(mg/dl) & Total Bilirubin & Indirect Bilirubin & Direct Bilirubin \\
\hline$\leq 1.0$ & 5 & 8 & 12 \\
\hline $1.1-5$ & 18 & 20 & 14 \\
\hline $5.1-10$ & 19 & 14 & 16 \\
\hline $10.1-15$ & 17 & 22 & 18 \\
\hline $15.1-20$ & 19 & 18 & 20 \\
\hline$\geq 20.1$ & 7 & 3 & 5 \\
\hline
\end{tabular}

Table 5: Serum ALT, AST and ALP level among serologically positive patients $(\mathrm{N}=85)$. Standard biological range for ALT, AST and ALP used in the study were 7-41U/L, 12-40U/L and 33-105U/L respectively.

\begin{tabular}{|c|c|c|c|}
\hline Range (U/L) & ALT(SGOT) & AST(SGPT) & ALP \\
\hline$<50$ & 15 & 31 & 0 \\
\hline $50-100$ & 10 & 15 & 10 \\
\hline $101-500$ & 29 & 18 & 65 \\
\hline $501-1000$ & 20 & 9 & 6 \\
\hline $1001-2001$ & 8 & 11 & 4 \\
\hline $2001-5000$ & 3 & 1 & 0 \\
\hline
\end{tabular}

=39, HAV=7, HEV and HAV dual infection=2)], followed by Hirapur $[\mathrm{n}=23(\mathrm{HEV}=15, \mathrm{HAV}=1)]$, Gudhiyari $[\mathrm{n}=9(\mathrm{HEV}=6)]$, Daganiya $[\mathrm{n}=5(\mathrm{HEV}=3)]$, Kabir Nagar $[\mathrm{n}=6(\mathrm{HEV}=4, \mathrm{HAV}=2)]$, Sunder Nagar $[\mathrm{n}=8(\mathrm{HEV}=6)]$ (Table 3$)$. Since DDU Nagar was the epicenter of this outbreak, the incidence rate extrapolated at the population of 28000 is calculated at $1.7 \%$. Area wise analysis revealed that majority of the HEV and HAV positive cases were found from DDU Nagar where in old rusted water pipe line were found contaminated with seepage from sewage pipelines.

Biochemical investigation revealed 50\% cases had total and direct bilirubin level greater than $10 \mathrm{mg} / \mathrm{dl}$. ALT and AST levels were raised $10-100$ times in $70 \%$ and $45 \%$ cases respectively. In $75 \%$ of cases the ALP level was raised, ranging between 101-500 unit/litre. More than 90\% cases had moderate to severely deranged LFT (Table 4 and 5).

The randomly picked 17 HEV ELISA positive samples were also found positive by nRT-PCR for HEV RNA, indicating HEV as major etiological factor (Figure 3). Further, sequencing and phylogenetic analysis of the five PCR products (GenBank accession number KT071749KT071753) from these samples revealed that the HEV strain was closely related (99\% at nucleotide level and $100 \%$ at amino acid level) to the HEV virus recently detected at Nepal (Gen Bank accession number AF 051830) and was belonging to genotype 1, subtype 1a which is the predominant type circulating in India. All the nucleotide sequences isolated from this outbreak were found nearly identical (Figure 4).

Follow up revealed no mortality in any of the cases under investigation probably due to timely diagnosis and medical intervention.

\section{Discussion}

Our study confirm the HEV as the prime etiological agent of this outbreak of acute hepatitis. This virus is documented to be a major cause of outbreaks of acute hepatitis in developing countries like India. It is reported as the cause of hepatitis outbreak as early as in 195556 from its first detection in Delhi [11] and since then continuously reported from various parts of the country viz., Kanpur [16], Rajasthan [17], Kolkata [18], Hyderabad [19], Girdharnagar, Ahmedabad [20], Punjab[21], with no molecular study has ever been reported from Chhattisgarh, Central India. To best of our knowledge this is the first confirmed report of HEV outbreak from this part of the country.

Higher male positivity (66.9\%) in comparison to female (33.0\%) was noticed in this outbreak, similar finding are documented from other parts of the country $[8,16,22]$. Significantly more number of adults in comparison to children was affected due to HEV, and this is a hallmark of HEV epidemiology. The affected age groups in this outbreak were analogous as reported earlier $[8,16]$. Death of eight pregnant women indicated the severity of HEV especially among this group as also corroborated by earlier studies [23,24]. Reason/s for the higher attack rate in men than women and children needs further epidemiological investigation.

The death of 23 patient's in initial stages of the outbreak on comparison with residential affected population reveals the mortality rate of 2.87 per 10,000 population, which was fairly higher. The clinical findings such as icterus, anorexia, pyrexia, abdominal pain, dark colored urine, nausea/vomiting, pain in right chondrium and laboratory biochemical investigations showing bilirubin level greater than $10 \mathrm{mg} / \mathrm{dl}$ and raised ALT, AST and ALP were similar as reported in other HEV outbreaks [25]. The raised levels of liver enzymes denote the devastating nature of these two viruses on hepatocytes and give the indirect indication of the virulent propensity of HEV and HAV. Thus, in this outbreak if the diagnostic and control measures were not initiated timely, it would have resulted in still higher mortality.

During the outbreak we also detected 10 cases of HAV indicating that HAV was also circulating. Two cases of co-infection were also detected. Interestingly, one of these cases was adult. However we did not noticed any significant difference in clinical presentation and laboratory findings among these three groups ie HEV, HAV and $\mathrm{HEV}+\mathrm{HAV}$ infected.

We report $9.4 \%$ prevalence of HAV. Recently, Barde et al have reported positivity of about $20 \%$ in hospitalized cases of HAV from Jabalpur, India [14]. Literature describe that there is overall decreasing trend in accordance with shifting patterns of seroprevalence over the past 20 years in Southeast Asia reflecting improved living standard and environmental hygiene $[26,27]$. HAV genotype III A was shown to be circulating in other part of central India [14], it would be worth to monitor the circulating genotype/s and shifting trends in this part of country to understand intricacies of epidemiology of HAV.

The molecular studies conducted confirmed the serological findings. Further the phylogenetic analysis on five representative samples confirmed that the HEV virus belongs to genotype 1a. Previous reports suggested that genotype1 and 4 are circulating in humans and pigs, respectively in India [28]. Sub-genotype 1a and 1c are detected from humans in India [7]. Further it is reported that the infecting genotype play a role determining severity of disease and transmission, and HEV genotype $1 \mathrm{c}$ is considered showing trends of severity and fulminant hepatitis [7,29]. Isolation and further characterization of the circulating HEV strains at molecular levels using long stretches of ORF, especially hyper variable regions of ORF 1 along with systematic clinical data would help in designing better control and treatment (intervention) strategies.

Both HEV and HAV are preventable infection through provision of clean drinking water. As the water pipelines were found contaminated with sewage drainage at several sites in the region, unsafe water consumption appeared to be the main reason of this outbreak Serological confirmation prompted the civic authorities to change the water pipelines and separate them from sewage drainage line.

In India and other developing countries endemic for water borne outbreak of HEV and HAV, Health and civic authorities should place some surveillance system to regularly monitor over a fixed period of time the portability of drinking water to avoid such preventable outbreak in future. 
Citation: Negi SS, Barde PV, Pathak R, Gaikwad U, Das P, et al. (2015) An Outbreak of Hepatitis E Virus in Raipur, Chhattisgarh, India in 2014: A Conventional and Genetic Analysis. J Med Microb Diagn 4: 209. doi:10.4172/2161-0703.1000209

Page 5 of 5

Our study has few limitations such as not testing chlorine content and coliforms in water samples, not testing samples of death cases owing to late initiation of outbreak investigation and high positivity to some extent as a result of hospital based study that might reflect the data of only critical and referred cases as some patients do not always present to tertiary care centre. Nevertheless this study has enough evidence that documents the first outbreak of HEV outbreak from central India.

It was concluded that the supply of fecally contaminated drinking water due to old and corroded pipelines passing close to old leaking sewage lines might have led to the outbreak of HEV. The regular epidemiological and microbiological surveys can contain any future outbreak and associated mortality and morbidity.

\section{Conflict of Interest: None}

\section{Acknowledgments}

Authors are thankful to the Secretary to Govt. of India, DHR, MoH\& FW, and The Director General, ICMR for financial support grant No.VIR/43/2011-ECD-1. PVB and RP would also like to thank Dr. Neeru Singh, Director, RMRCT for her kind support. The technical help of Mr. Uttam Singh Uikey, Technical Assistant, Virology laboratory, AIIMS, Raipur and staff of Virology Department of RMRCT, Jabalpur is highly acknowledged.

\section{Authors Contributions}

SSN, BA and PVB designed the study. RP conducted nRT-PCRs. SSN, UG and PD did clinical investigations and data analysis. RP and PVB did sequencing and phylogenetic analysis. SSN, BA, PVB and RP prepared the MS. All authors read and agreed upon the manuscript.

\section{References}

1. (http : // www.who.int / mediacentre / factsheets / fs 280 / en /)

2. (http : // www.who.int / mediacentre / factsheets / fs328 / en /).

3. Irshad M, Singh S, Ansari Ma, JoshiYK (2010) Viral hepatitis in India; A report from Delhi. Global J Health Sci 2: 96-103.

4. Kumar S, Subhadra S, Bhupinder S, Panda BK (2013) Hepatitis E virus: the current scenario. Int J Infect Dis17: 228 - 233.

5. Chandra V, Taneja S, Kalia M, Jameel S (2008) Moleculr biology and pathogenesis of hepatitis $E$ virus. $J$ biosci 33: 451-464.

6. Panda SK, Thakral D, Rehman S (2007) Hepatitis E virus. Reviews Med Viro 17: $151-180$

7. Chandra NS, Rai RR, Malhotra B (2012) Phylogenetic analysis of hepatitis E virus in Northwest India. Hepatitis Res Treat

8. Vivek R, Nihal L, Illiayaraja J, Reddy PK, Sarkar R, et al. (2010) Investigation of an epidemic of Hepatitis $E$ in Nellore in south India. Trop Med Int Health 15: 1333-1339.

9. Salija B, Murhekar MV, Hutin YJ, Kuruva SK (2009) Outbreak of waterborne hepatitis E in Hyderabad, India, 2005. Epidemiol Infect 137: 234-240.

10. Singh J, Prakash C, Panda R, Bora D, Jain DC, et al.(1998) Acute sporadic viral hepatitis in urban population of a tribal district in Madhya Pradesh. Ind Ped 35: 105-109.

11. Vishwanathan R (1957) Infectious hepatitis in Delhi (1955-1956): a critical study-epidemiology. Indian J Med Res 26: 362-379.

12. Kumar S, Ratho RK, Chawla YK, Chakraborti A (2007) The incidence of sporadic viral hepatitis in North India: a preliminary study. Hepatobiliary Pancreat Dis Int 6: 596-599.

13. Arankalle, Paranjape S, Amerson SU, Purcell RH, Walimbe AM (1999) Phylogenetic analysis of hepatitis E virus isolates from India(1976-1993). J Gen Virol 80: 1691-1700.

14. Barde PV, Shukla MK, Pathak R, Kori BK, Bharti PK (2014) Circulation of hepatitis A genotype IIIA virus in paediatric patients in central India. Indian $J$ Med Res 139: 940-944.

15. Tamura K, Peterson D, Peterson N, Stecher G, Nei M, et al. (2011) MEGA 5: molecular evolutionary genetics analysis using maximum likelihood, evolutionary distance, and maximum parsimony methods. Mol Biol Evol 28 2731-2739.

16. Naik SR, Aggarwal R, Salunke PN, Mehrotra NN (1992) A large waterborne viral hepatitis E epidemic in Kanpur, India. Bull World Health Organ 70: 597604

17. Gupta RS, Jain DC, Bandyopadhyay S, Meena VR, Prakash C, et al. (1995) An outbreak of viral hepatitis in Jodhpur city of Rajasthan. J Commu Dis 27 $175-80$.

18. Das P, Adhikary KK, Gupta PK (2007) An Outbreak Investigation of Vira Hepatitis $\mathrm{E}$ in South dumdum municipality of Kolkata. Indian J Community Med 32: $84-85$

19. Sailaja B, Murhekar MV, Hutin YJ, Kuruva S, Murthy SP, et al. (2009) Outbreak of waterborne hepatitis E in Hyderabad, India, 2005. Epidemiol Infect 137: 234 240.

20. Chauhan NT, Prajapati P, Trivedi AV, Bhagyalaxmi A (2010) Epidemic Investigation of the Jaundice Outbreak in Girdharnagar, Ahmedabad, Gujarat, India, 2008. Indian J Community Med 35: 294-297.

21. Arora D, Jindal N, Shukla RK, Bansal R (2013) Waterborne hepatitis A \& Hepatitis E in Malwa region of Punjab, India. J Clin Diagn Res 7: 2163-2166.

22. Tsega E, Hansson BG, Krawczynski K, Nordenfelt E (1992) Acute sporadic viral hepatitis in Ethiopia: causes, risk factors, and effects on pregnancy. Clin Infect Dis 14: 961-965

23. Gurley ES, Hossain MJ, Paul RC, Sazzad HMS, Islam MS, et al. (2014) Outbreak of Hepatitis $\mathrm{E}$ in urban Bangladesh resulting in Maternal and perinantal mortality. Clin Infect Dis 59: 658-65.

24. Patra S, Kumar A, Trivedi SS, Puri M, Sarin SK (2007) Maternal and fetal outcomes in pregnant women with acute hepatitis $E$ virus infection. Ann Intern Med 147: 28-33.

25. Eyasu HT, Dale JH, Scott DH (2010) The Two Faces of Hepatitis E Virus. Clin Infect Dis 51: 328-334.

26. Murhekar MV, Sehgal SC, Murhekar KM, Padbhidri SP, Chitamber SD, et al. (2002) Changing scenario of Hepatitis A virus and Hepatitis E virus exposure among the primitive tribes of Andaman \& Nicobar islands, India over the 10year period 1989-99. J Viral Hepatitis 9: 315-21.

27. Acharya SK, BatraY, Bhatkal B (2003) Sero epidemiology of Hepatitis A virus infection among school children in Delhi and North Indian patients with chronic liver disease: implication for HAV vaccination. J Gastroenterol Hepatol 18: 822-827.

28. Arankalle VA, Lole KS, Deshmukh TM, Chobe LP, Gandhe SS (2007) Evaulation of human(genotype1) and swine(genotype 4) ORF2based ELISAs for anti HEV IgM and IgG detection in an endemic country and search for type 4 human HEV infections. J Viral Hepatitis 12: 435-445.

29. Pujhari SK, Kumar S, Ratho RK, Chawla YK, Chakraborti A (2010) Phylogenetic analysis and subtyping of acute and fulminant strains of hepatitis $E$ virus isolates of North India with reference to disease severity. Arch Virol 155: 1483-1486. 